\title{
The Computer Arts Archive
}

\author{
Sean Clark \\ Interact Digital Arts Ltd \\ Leicester, UK \\ seanc@interactdigitalarts.uk
}

\begin{abstract}
The newly-established Computer Arts Archive provides a home for The CAS50 Collection and related materials from the Computer Arts Society, plus those of individual artists. The archive was incorporated as a Community Interest Company in January 2020 and now has an office and storage facility in Leicester. This paper documents the recent additions to the archive and the exhibitions undertaken in 2019 at the Royal College of Arts in London, the LCB LightBox Gallery in Leicester and at the V\&A in London. It also presents a strategy for developing the archive further that involves expanding the types of work collected and the amount of contextualising materials.
\end{abstract}

Digital art. Computer art. Preservation. Art history.

\section{INTRODUCTION}

The CAS50 Collection began as a project to help celebrate the 50th anniversary of the creation of the Computer Arts Society in 1968. In 2018, two exhibitions of artist-contributed work were held, one in Leicester and one in Brighton. This was then followed by a new phase of collecting in 2019 and two additional exhibitions in London and then Leicester again.

In the conclusion to my paper reporting on the progress of the Collection at EVA London 2019, I stated that, "if the collection is to progress beyond two of three phases of curation then a permanent home for it will need to be found" (Clark 2019). This paper presents the latest additions to the CAS50 Collection and introduces its new home in Leicester, the Computer Arts Archive.

\section{THE CAS50 COLLECTION: PHASE 2}

The initial set of artworks (now referred to as Phase 1) making up what was to become the CAS50 Collection featured printed works by Stephen Bell, Peter Beyls, boredomresearch, Daniel Brown, Paul Brown, Sean Clark, Ernest Edmonds, Sue Gollifer, Desmond Henry, William Latham, Andy Lomas and Stephen Scrivener (see Clark 2018; available for download). The artists were approached directly about contributing and all agreed to donate work to the project for free.

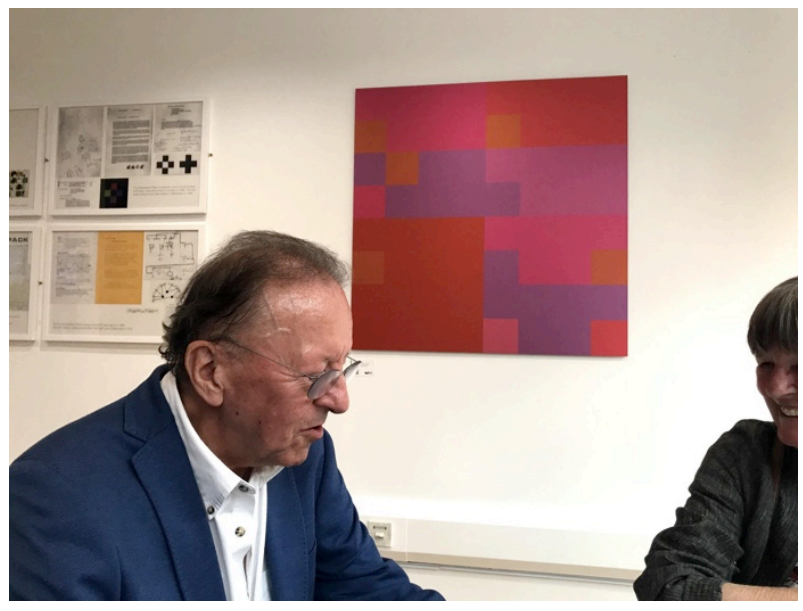

Figure 1: Ernest Edmonds (left) pictured with Shaped Forms, Venice-CAS (2018). Digital print on aluminium.

Within this first phase of collection, a variety of themes can already be seen. For example, a number of the artists create work that is influenced by natural forms. This is certainly true of the pieces contributed by Stephen Bell, boredomresearch, Daniel Brown, William Latham and Andy Lomas. Others - such as the work Sean Clark, Ernest Edmonds (see Figure 1) and Stephen Scrivener represent what might be seen as a more 'abstract', systems-based, approach to computer image generation.

There are associations within the collection based on institutions, such as the Goldsmiths link between William Latham and Andy Lomas. A 
number of the artists featured attended the Slade School (Stephen Bell, Peter Beyls, Paul Brown \& Stephen Scrivener). There are also personal connections, such as with Stephen Bell, Sean Clark and Stephen Scrivener, all of whom studied under Ernest Edmonds.

For the second phase of collecting, twelve artists were approached with the aim of strengthening some of the connections within the collection and introducing some new ones. There was also a conscious effect to address some of the deficiencies, most notably the gender balance, with only two of the Phase 1 artists being female (Sue Gollifer and Vicky Isely from boredomresearch).

As with Phase 1, all artists were approached directly and agreed to donate their artwork for free. The artists in Phase 2 were Damien Borowik, Anna Dumitriu, Genetic Moo, Gibson/Martelli (see Figure 2), Alex May, Gordana Novaković, Fabrizio Poltronieri, Esther Rolinson, Roger Saunders, Brian Reffin Smith, Jack Tait and Patrick Tresset.

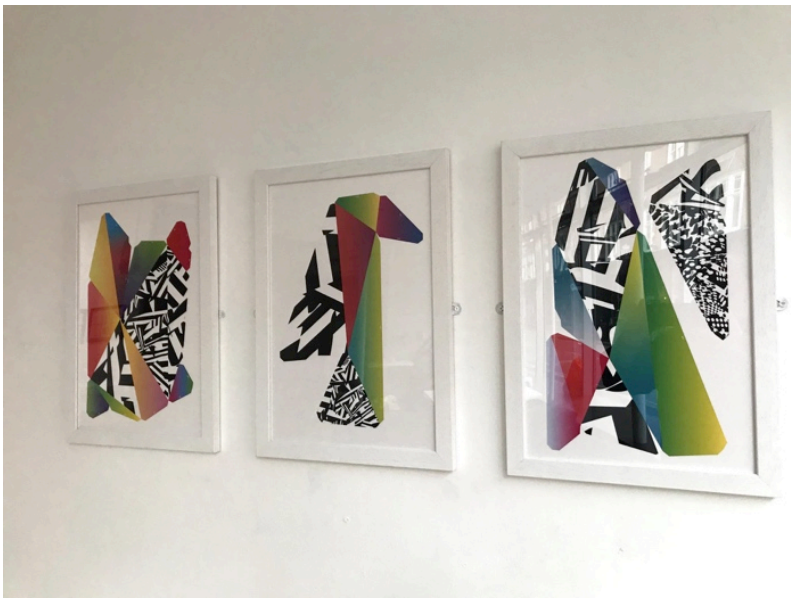

Figure 2: MAN-A prints (2016) in the collection by Gibson/Martelli.

This represents a better, if not totally equal, gender balance with Anna Dumitriu, Nicola Schauerman of Genetic Moo, Ruth Gibson of Gibson/Martelli, Gordana Novaković and Esther Rolinson being included. A number of these female artists were also included in the 2016 exhibition "Technology is Not Neutral", curated by Anna Dumitriu, Gordana Novaković and Irini Papadimitriou (Dumitriu et al. 2016). The Computer Arts Archive is having an ongoing dialogue with the organisers of this exhibition to ensure that the gender balance continues to be addressed.

Something that builds on the first phase of collecting is the inclusion of a number of Lumen Prize winners, bringing the total number of winners represented in the collection to seven (Genetic
Moo, Gibson/Martelli, Patrick Tresset joining boredomresearch, Andy Lomas, Sean Clark and Esther Rolinson).

Given that the work in the collection is primarily onpaper (boredomresearch and Ernest Edmonds donated aluminium prints), there was also a concerted eon paper ensure that the full range of paper-based printing processes were represented). To this end, computer drawings by Damien Borowik, Jack Tait, Patrick Tresset were included. Work by these artists, together with Esther Rolison, was included in the exhibition "Computer Drawing: DP Henry and Beyond", curated by Sean Clark in 2015 (Interact Digital Arts - Computer Drawing DP Henry and Beyond, 2020). The pieces acquired for this earlier exhibition have now been given to the CAS50 Collection on long-term loan.

Two early 1970s computer printouts by Roger Saunders (see Figure 3) have also been added to the collection. Brian Reffin Smith's contribution includes a plotter drawing as well as a print, and there is an "algorithmic photograph" by Alex May and photographs of a performance by Anna Dumitriu. This represents a marked difference in media from Phase 1, where most of the work was inkjet printed, the exceptions being that of Desmond Henry (computer drawing) and Stephen Scrivener (computer printout).

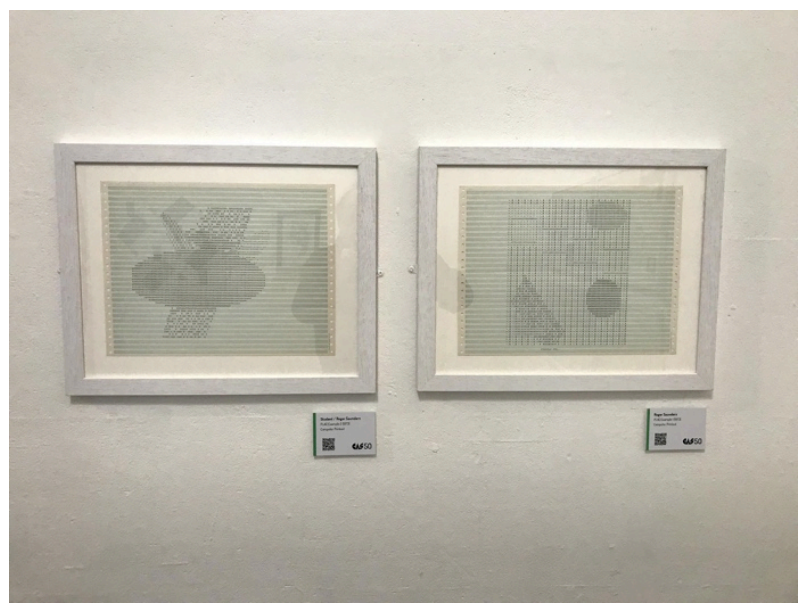

Figure 3: Computer printouts dating from the early 1970s by Roger Saunders.

The addition of these twelve new artists meant that a total of 24 artists were represented in The CAS50 Collection following the Phase 2 collecting process. Some artists donated more than one piece, resulting in a total collection that currently contains around 40 artworks. All of the work in the collection has been produced using computational techniques and is presented through a range of printing and drawing techniques. 


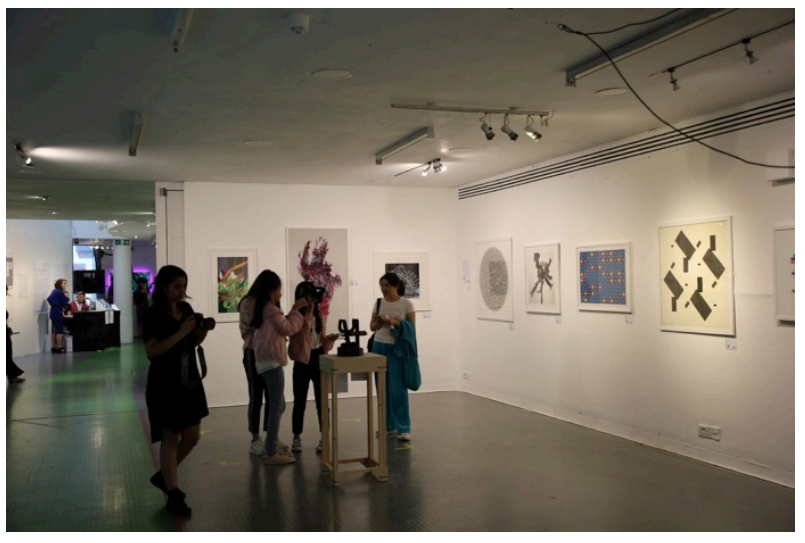

Figure 4: Event Two at the Royal College of Art, July 2019.

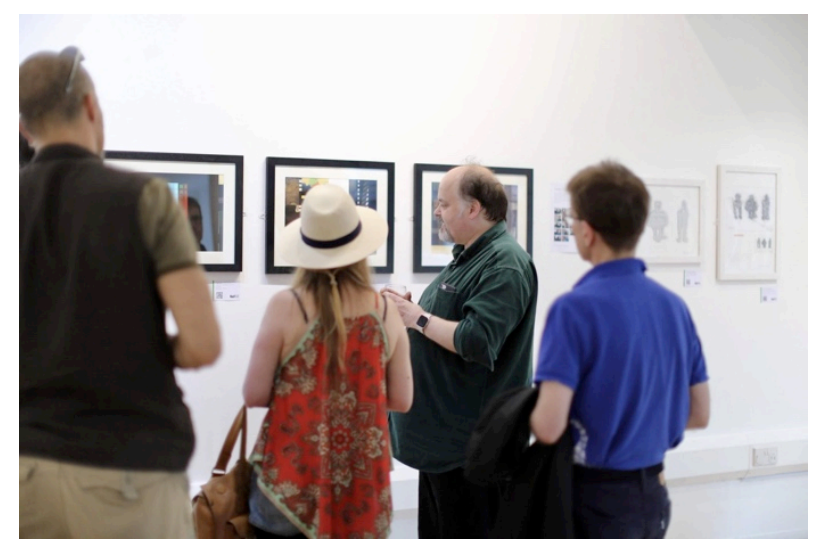

Figure 5: The CAS50 Collection at the LCB Depot LightBox Gallery in Leicester, July/August 2019.

\section{EVENT TWO AT THE ROYAL COLLEGE OF ART}

The first opportunity to exhibit the expanded CAS50 Collection came in early July 2019 (from the 12th until the 17th) as part of the Event Two exhibition at the Royal College of Art. This exhibition, seen as a "sequel" to the Computer Arts Society's Event One in 1969 (documented by Mason 2009), saw the complete CAS50 Collection on show, together with a set of contemporary and interactive artworks curated by Art In Flux, plus audio and video showreels, a timeline by Nick Lambert and interviews with artists undertaken by David Upton. Additionally, two pieces by pioneering computer artist Harold Cohen were included from the author's own collection (now on long-term loan to the CAS50 Collection. There were also evening events hosted by EVA London, Art In Flux, the Computer Arts Society and Lumen Art Projects, the organisers of the Lumen Prize.

All of the evening events during Event Two were fully booked, and the number of attendees during the day was in the thousands. The success of the event was a testament to the effort of all of those involved in the organisation of the event, including
Graham Diprose from the EVA London conference committee.

Event Two has been extensively documented on the Computer Arts Society website (Computer Arts Society - Event Two, 2020). Materials captured include photographs, videos, 3D images and panoramic images. On the website there is also a full set of acknowledgements and thanks to the many people involved in the event.

Unlike Event One in 1969, where images of the exhibition were "rare" (as noted by Catherine Mason in the caption to a single image of the exhibition in her 2009 EVA paper. Mason 2009), curators a future "Event Three" in 2069 will have access to a wealth of documentary materials from their preceding show. These are now seen as Phase 3 of The CAS50 Collection, and will be preserved accordingly.

\section{CAS50 AT THE LCB DEPOT 2019}

Event Two was followed by an exhibition of the work by the twelve CAS50 Collection Phase 2 artists at the LCB Depot LightBox Gallery in Leicester. The exhibition took place between 22nd July and 7th August 2019, just over a year after the first CAS50 exhibition in 2018. While smaller than Event Two, the Leicester exhibition was also well attended and was accompanied by a talk and live event. Documentary materials from the exhibition and live event can be found on the Interact Digital Arts website (Interact Digital Arts 2020). The exhibition, live event, together with the showing of The CAS50 Collection at Event Two was supported by an Arts Council England project grant awarded to Interact Digital Arts.

\section{EVENT TWO AT THE VICTORIA \& ALBERT MUSEUM}

The Leicester exhibition was intended to be the finale of the Computer Arts Society's fiftieth year celebration. However, an opportunity was offered to show work from the collection as part of the V\&A Digital Design Weekend on the 21st and 22nd September 2019. Artwork by Stephen Bell, Desmond Henry, William Latham, Alex May and Stephen Scrivener was shown, together with work curated by the Art In Flux group.

\section{A STRATEGY FOR COLLECTING COMPUTER ART}

The first two phases of The CAS50 Collection have focussed on printed works and other works on paper. As previously discussed, effort has been made to ensure that a range of different production 
methods are represented, but clearly a computer art collection could, and perhaps should, look beyond this.

A strategy has therefore been developed for the future of the collection that will enable it to grow and diversify. Central to this a model in which different forms of digital and computer artworks are ordered according to their ease of collection and maintenance. The expectation is that those further down the list will be less represented in the collection. The types of digital artworks to be collected are shown in Table 1.

Table 1: The digital artworks to be collected in CAS50 Collection, ordered by ease of collecting and maintenance.

\begin{tabular}{|c|l|}
\hline \multicolumn{2}{|l|}{ DIGITAL ARTWORKS } \\
\hline $\mathbf{1}$ & $\begin{array}{l}\text { Printed Works } \\
\text { On paper and other media. }\end{array}$ \\
\hline $\mathbf{2}$ & $\begin{array}{l}\text { Video Works } \\
\text { On physical media and in digital form. }\end{array}$ \\
\hline $\mathbf{3}$ & $\begin{array}{l}\text { Screen-based Works } \\
\text { Recorded as long video loops. }\end{array}$ \\
\hline $\mathbf{4}$ & $\begin{array}{l}\text { Screen-based Works } \\
\text { Using standard computer hardware and software. }\end{array}$ \\
\hline $\mathbf{5}$ & $\begin{array}{l}\text { Screen-based Works } \\
\text { Using specialist computer hardware and } \\
\text { software. }\end{array}$ \\
\hline $\mathbf{6}$ & $\begin{array}{l}\text { Installation Works } \\
\text { Physical artworks using custom computer } \\
\text { hardware and software. }\end{array}$ \\
\hline
\end{tabular}

Note that this model suggests that the CAS50 Collection is still in its very early stages, with scope to move on to video works, screen-based work and digital installation artworks. A separation is made between recordings of screen-based works, where generative artworks are recorded on long video loops for ease of preservation and presentation, and the screen-based artworks themselves. This type of work is then divided into screen-based works that are produced using standard, more preservable, technologies, and those that use specialist systems, that are likely to be harder to preserve and exhibit. Finally, there is an ambition to include installation artworks in the collection, which may require specialist computer hardware and software.

In addition to digital artworks themselves, contextualising materials will also be collected, starting with books, catalogues and other 'ephemera' and working up to include documentary materials, interviews and artist monologues and algorithms and so on. This is shown in Table 2.

Table 2: The contextualising materials to be collected in CAS50 Collection.

\begin{tabular}{|c|l|}
\hline \multicolumn{2}{|l|}{ CONTEXTUALISING MATERIALS } \\
\hline $\mathbf{1}$ & $\begin{array}{l}\text { Publications } \\
\text { Books, papers, reviews etc. }\end{array}$ \\
\hline $\mathbf{2}$ & $\begin{array}{l}\text { Ephemera } \\
\text { Catalogues, flyers, publicity materials etc. }\end{array}$ \\
\hline $\mathbf{3}$ & $\begin{array}{l}\text { Documentary Materials } \\
\text { Multimedia materials collected at exhibitions. }\end{array}$ \\
\hline $\mathbf{4}$ & $\begin{array}{l}\text { Artist Interviews } \\
\text { Audio/video interviews with artists. }\end{array}$ \\
\hline $\mathbf{5}$ & $\begin{array}{l}\text { Algorithms and Explanations } \\
\text { Detailed information about the make-up of digital } \\
\text { artworks. }\end{array}$ \\
\hline
\end{tabular}

The most detailed type of contextualisation, Type 5, would provide sufficient information to enable even the most complicated digital artwork to be recreated and subsequently exhibited. Work is presently underway to apply this approach to the collection of artworks in the Shaping Form series by Ernest Edmonds (Edmonds 2007; 2017).

\section{THE COMPUTER ARTS ARCHIVE}

As mentioned above, the CAS50 collection now extends to 40 printed items. Additionally, in keeping with the strategy above, works on videotape are being acquired, as well as publications and ephemera. This creates two immediate issues: 1) where is this material stored, and 2) who owns it?

The solution to both of these issues has been to establish a new social enterprise called the Computer Arts Archive Community Interest Company $(\mathrm{ClC})$. The $\mathrm{CIC}$ was incorporated on the 2nd January 2020 as a non-profit with the following objectives:

The Computer Arts Archive is a non-profit company that collects, exhibits and promotes computer artwork for the benefit of artists, audiences, curators, educators and researchers. It collaborates with other collections, museums and galleries to explore the impact of digital culture and ensure that computer art is recognised as a significant contemporary art form with a rich and diverse history. In particular, we work closely with the Computer Arts Society, a member-based organisation founded in 1968. 
The $\mathrm{CIC}$ has subsequently rented an office and storage space at the LCB Depot in Leicester. This will enable The CAS50 Collection to be safely stored between exhibitions. Additionally, a process has been initiated to formally transfer the ownership of the collection to the Computer Arts Archive $\mathrm{CIC}$, together with procedures for long-term loan and future donations.

\section{Computer Arts Ar<hive}

Figure 6: The logotype for the new Computer Arts Archive CIC.

A business plan for the ongoing maintenance of the new Computer Arts Archive $\mathrm{CIC}$ has been produced by Interact Digital Arts. This looks to bring income into the project through individual and corporate donations, as well as grant applications to Arts Council England and the UK's National Lottery Heritage Fund.

Future progress on the development of The CAS50 Collection and the Computer Arts Archive CIC will be reported via the in-progress website at https://computer-arts-archive.com. People wishing to donate money or artwork to the archive can contact computerartsarchive@gmail.com.

\section{REFERENCES}

Clark, S. (2018) CAS50: Celebrating Fifty Years of the Computer Arts Society. Interact Digital Arts (October 2018) ISBN 978-1-9993103-0-1. Available from: http://bit.ly/2Qwv1tY

Clark, S (2019) The CAS50 Exhibition and Collection. Proceedings of the EVA 2019 Conference, 8-11 July 2019. BCS, London.

Computer Arts Society -CAS50 Collection. https://computer-arts-society.com/cas50-collection (retrieved 25 March 2020).

Computer Arts Society - Event Two. http://computer-arts-society.com/archive (retrieved 25 March 2020).

Edmonds, E. A. (2007) Shaping Form Series. In Jennings, O. Speculative Data and the Creative Imaginary. National Academy of Sciences, Washington DC. pp 18-9.

Edmonds, E. A. (2017) Shaping Form 17. CHI EA'17 Extended Abstracts on Human Factors in Computing Systems. ACM New York, NY. pp.1431-1432.

Interact Digital Arts - CAS50 Collection 2019. http://interactdigitalarts.uk/cas50 (retrieved 25 March 2020).

Interact Digital Arts - Computer Drawing DP Henry and Beyond. https://interactdigitalarts.uk/computerdrawing-exhibition (retrieved 25 March 2020).

Mason, C. (2009) The Fortieth Anniversary of Event one at the Royal College of Art. Proceedings of the EVA 2009 Conference, 6-8 July 2009. BCS, London. 